\title{
Study on primary carbides precipitation in H13 tool steel regarding cooling rate during solidification
}

\author{
*Guang-di Zhao', Xi-min Zang', Wan-ming Li ${ }^{1}$, Zhuo Zhao', De-jun Li ${ }^{2}$ \\ 1. School of Materials and Metallurgy, University of Science and Technology Liaoning, Anshan 114051, China \\ 2. State Key Laboratory of Marine Equipment and Applications, Anshan, 114051, China
}

\begin{abstract}
This study aims to investigate the primary carbides precipitation in $\mathrm{H} 13$ steel solidified at relatively high cooling rates, ranging from 300 to $6,000{ }^{\circ} \mathrm{C} \cdot \mathrm{min}^{-1}$, based on in situ observations with a high temperature confocal laser scanning microscope. In the cooling rate range investigated, the solidification microstructure becomes more refined as cooling rate increases and the relationship between the secondary dendrite arm spacing (SDAS), $\lambda_{2}$, and cooling rate, $\dot{T}$, can be expressed as $\lambda_{2}=128.45 \dot{T}^{-0.124}$. Regardless of cooling rates, two kinds of primary carbides, i.e., the Mo-Cr-rich and V-rich carbides, are precipitated along the interdendritic region and most of them are the Mo-Cr-rich carbides. The morphology of Mo-Cr-rich carbide is not obviously influenced by the cooling rate, but that of $\mathrm{V}$-rich carbide is obviously affected. The increasing cooling rate markedly refines the primary carbides and reduces their volume fractions, but their precipitations cannot be inhibited even when the cooling rate is increased to $6,000{ }^{\circ} \mathrm{C} \cdot \mathrm{min}^{-1}$. Besides, the segregation ratios (SRs) of the carbides forming elements are not obviously affected by the cooling rate. However, compared with the conventionally cast ingot, the SDAS and primary carbides in the steel solidified at the investigated cooling rates are much finer, morphologies of the carbides have changed significantly, and SRs of the carbides forming elements are markedly greater. The variation of primary carbide characteristics with cooling rate is mainly due to the change in SDAS.
\end{abstract}

Key words: H13 steel; cooling rate; solidification; primary carbides

CLC numbers: TG142.45; Document code: A;

Article ID: 1672-6421(2020)03-235-10

\begin{abstract}
A ISI H13 hot-work tool steel with extraordinary hot strength and remarkable toughness is widely used for the manufacturing of molds and dies for extrusion, forging and die casting tools ${ }^{[1-4]}$. However, nonequilibrium primary carbides are usually precipitated at the final stage of H13 solidification due to the dendritic segregation ${ }^{[5-7]}$, which is considered to be unfavorable for the final mechanical properties of the molds and dies ${ }^{[8,9]}$.

The H13 steel is generally produced by conventional processes, such as casting, electro-slag remelting (ESR) and powder metallurgy $(\mathrm{PM})^{[5,10]}$. However, these processes have serious drawbacks. For instance, the conventional casting process with a lower solidification cooling rate leads to a coarse dendritic structure and the precipitation of coarse primary carbides in the interdendritic region, which are unfavorable for achieving the best mechanical properties ${ }^{[7,11,12]}$. During the ESR process, the molten slag above the ingot/pool interface
\end{abstract}

\footnotetext{
*Guang-di Zhao
}

Male, born in 1989, Lecturer, Ph.D. His research interests mainly focus on the solidification and segregation behaviors of metals.

E-mail: gdzhao12s@alum.imr.ac.cn

Received: 2019-10-08; Accepted: 2020-02-01 acts as a heat reservoir, which leads to a larger mushy zone and in turn promotes chemical heterogeneity ${ }^{[13]}$. Although the PM process can control the microstructureproperty relations better, the process is very complicated and the equipment is too expensive ${ }^{[10]}$. Additive manufacturing (AM) has generated great interest in the public and industrial sectors over the past several decades ${ }^{[14]}$. This procedure has a number of advantages over the conventional processes above. For example, the AM allows the production of complex geometries ${ }^{[15]}$. Expensive molds or dies are not necessary for AM, which opens a potential for reduction of cost ${ }^{[16]}$. Moreover, AM can lead to extended solute trapping in the solid state, and refine the microstructure due to the fast solidification cooling rate (usually higher than $1,800^{\circ} \mathrm{C} \cdot \mathrm{min}^{-1}{ }^{[17-21]}$. Nevertheless, $\mathrm{AM}$ is seldom used for manufacturing mechanical parts made up of hot-work tool steels. Recently, Klocke et al. ${ }^{[22]}$ suggested that AM has the potential to build and/or repair dies and molds of hot-work tool steels, and this crucial emerging field is set to grow rapidly over the coming years. In this case, it is necessary to investigate the characteristics of primary carbides in H13 steel solidified at relatively high cooling 
rates (close to the cooling rates of AM processes), which is helpful for understanding the microstructure evolution during AM processes. Besides, figuring out how the cooling rate influences the primary carbides precipitation could provide theoretical support for AM process design of H13 steel. Mao et al. ${ }^{[5]}$ studied the precipitation of primary carbides in $\mathrm{H} 13$ steel in the cooling rate range of $5-20^{\circ} \mathrm{C} \cdot \mathrm{min}^{-1}$, but the cooling rates are much lower than those of AM processes.

The high temperature confocal laser scanning microscope (HTCLSM) can be used for in situ observation of the solidification process of metals at cooling rates up to $6,000{ }^{\circ} \mathrm{C} \cdot \mathrm{min}^{-1}[23-25]$. Therefore, in the present study, a HT-CLSM (VL2000DXSVF18SP) was used to investigate the primary carbides precipitation in $\mathrm{H} 13$ steel solidified at relatively high cooling rates $\left(300-6,000{ }^{\circ} \mathrm{C} \cdot \mathrm{min}^{-1}\right)$. Quantitative relationships between the secondary dendrite arm spacing (SDAS) and cooling rate were determined, and the mechanism by which the cooling rate influencing the primary carbides precipitation was discussed.

\section{Experimental procedure}

The H13 melt was prepared in a medium frequency induction melting furnace from $2.25 \mathrm{Cr}-1 \mathrm{Mo}(\mathrm{P} 22)$ steel and $\mathrm{H} 13$ scrap steel, and was poured at about $1,540{ }^{\circ} \mathrm{C}$ into a cast iron mould to produce an ingot of $\Phi 200 \mathrm{~mm}$. The chemical composition of the steel is shown in Table 1.

Table 1: Chemical compositions of the experimental steel $(w t . \%)$

\begin{tabular}{ccccccccc} 
C & Si & Mn & Cr & Mo & V & P & S & Fe \\
\hline 0.53 & 1.09 & 0.25 & 6.68 & 2.15 & 1.11 & 0.024 & 0.008 & Bal.
\end{tabular}

Four cylindrical samples of $\Phi 8 \mathrm{~mm} \times 3 \mathrm{~mm}$ were cut from the half radius of the ingot by electron discharge machine. Afterwards, the samples were ground and polished to a mirror finish. One of the polished samples was etched with $4 \%$ nital solution and then observed under an optical microscope (OM), a field emission-scanning electron microscope (FESEM) equipped with a back scattered electron detector (BSE), and an energy dispersive spectrometer (EDS) to reveal the microstructure of the conventionally cast ingot. The other three polished samples were used for the HT-CLSM tests. The schematic diagram of the HT-CLSM is shown in Fig. 1(a). A halogen lamp was fixed as a heating source at the lower focal point of the ellipsoidal gold-plated infrared image furnace chamber and focused at upper focal point of the chamber. The sample was placed in an alumina crucible and then put at the upper focal point. The alumina crucible was placed on a Pt stage welded with a thermocouple. In order to prevent the oxidation of the surface of the sample, the chamber was constantly filled with high purity argon. The recorded temperature-time profiles of the samples are shown in Fig. 1(b). The samples were firstly heated to $200{ }^{\circ} \mathrm{C}$ at a heating rate of $40^{\circ} \mathrm{C} \cdot \mathrm{min}^{-1}$, and then were heated to $1,300{ }^{\circ} \mathrm{C}$ at a heating rate of $180{ }^{\circ} \mathrm{C} \cdot \mathrm{min}^{-1}$. In order to prevent the samples from completely melting and collapsing due to excessive heating, they were manually heated from 1,300 to $1,400{ }^{\circ} \mathrm{C}$, and held for $1-2 \mathrm{~min}$ to homogenize the liquid phase. Finally, the samples were cooled to room temperature at a cooling rate of $300,1,200$ and $6,000{ }^{\circ} \mathrm{C} \cdot \mathrm{min}^{-1}$, respectively. The heating processes and the $300{ }^{\circ} \mathrm{C} \cdot \mathrm{min}^{-1}$ cooling process were achieved by modifying the input power of the halogen lamp, while the 1,200 and $6,000{ }^{\circ} \mathrm{C} \cdot \mathrm{min}^{-1}$ cooling processes (higher cooling rates) could only be achieved by filling the chamber with $\mathrm{He}$ gas and controlling the input power of the halogen lamp simultaneously. Note that since the thermocouple is welded to the Pt stage, there must be some difference between the actual temperature of the sample surface and the measured temperature ${ }^{[23,26,27]}$. Subsequently, the upper surfaces of the HT-CLSM samples solidified at different cooling rates were also polished and etched with $4 \%$ nital solution. Their microstructures were also observed under the OM and FE-SEM.

The secondary dendrite arm spacings (SDASs), $\lambda_{2}$, of the conventionally cast ingot and HT-CLSM samples were measured in the optical images using the linear intercept method. It is reported that the areal fraction, $f_{\mathrm{sa}}$, obtained on two dimensional sections is representative of the volume fraction, $f_{\mathrm{s}}^{[28]}$ :

$$
f_{\mathrm{s}}=\sum A_{\alpha} / A_{\mathrm{T}}=f_{\mathrm{sa}}
$$

where, $\sum A_{\alpha}$ is the sum of the areas of primary carbides, and $A_{\mathrm{T}}$ is the total measurement area. Thus volume fractions of the primary carbides formed in the conventionally cast ingot and HT-CLSM samples were determined using the Image Pro (a)

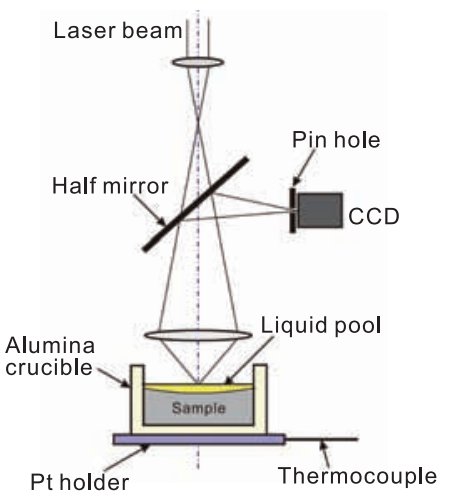

(b)

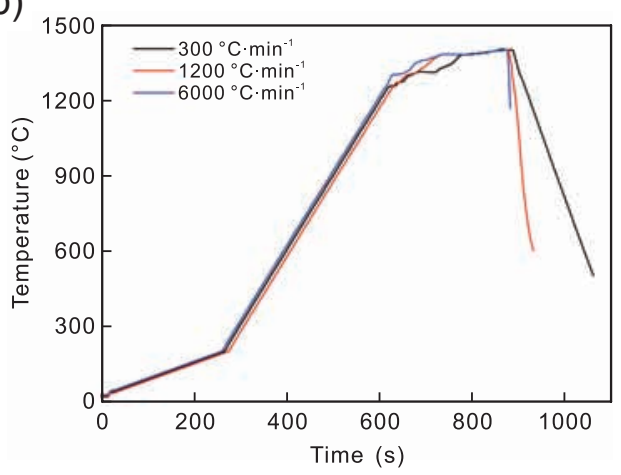

Fig. 1: Schematic illustration (a) and recorded temperature-time profiles (b) for HT-CLSM tests 
Plus 6.0 image analysis software based on the areal analysis. In order to guarantee the reliability of the measured results, ten micrographs were taken from the conventionally cast sample using OM, and five micrographs were taken from each HT-CLSM sample using SEM-BSE to calculate the average values.

Compositions in the interdendritic region around the primary carbides and dendrite core of the conventionally cast ingot and HT-CLSM samples were determined by the rectangular region X-ray acquisition method using the SEM-EDS. The segregation ratio (SR) defined as the ratio of the interdendritic region to dendrite core composition was used to describe the dendritic segregation. At least five positions of each region were selected to calculate the average values.

\section{Results and discussion}

\subsection{Microstructures of conventionally cast ingot}

Figure 2 shows the dendritic structure of the conventionally cast H13 steel ingot under optical microscope. The dendrite core appears with a bright color and the interdendritic region appears with a dark color. The average SDAS is $122.7 \pm 13.5 \mu \mathrm{m}$. Stripy and blocky particles with a length of 20-80 $\mu \mathrm{m}$ were observed in the interdendritic region, and the volume fraction of the particles was calculated to be $0.53 \pm 0.07$ (\%).

The particles located in the interdendritic region were further observed under the SEM-BSE, and their compositions were analyzed using the SEM-EDS. The SEM-BSE observation shows that the particles are composed of two kinds of phases

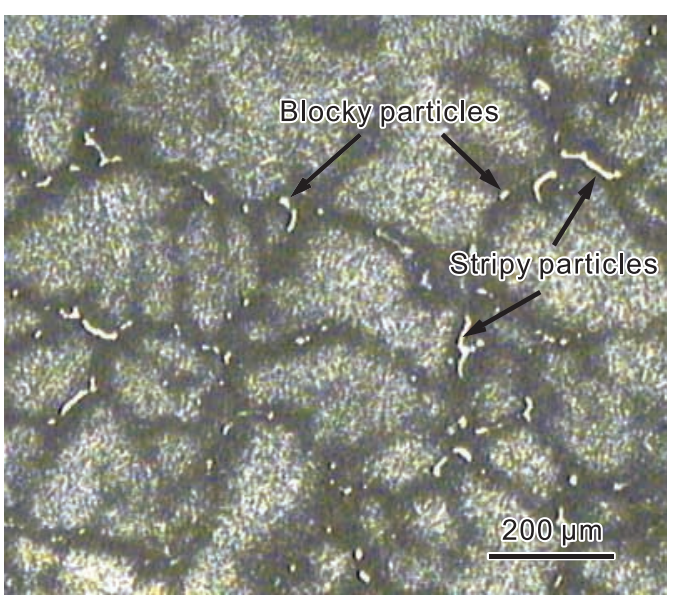

Fig. 2: Dendritic structure of conventionally cast $\mathrm{H} 13$ steel ingot

(Fig. 3). The EDS analysis suggests the phase with a bright color is the Mo-Cr-rich primary carbide (Fig. 4a), and that with a gray color is the V-rich primary carbide (Fig. 4b). The MoCr-rich carbide is always attached to the V-rich carbide and their morphologies are similar. Apparently, these particles are the primary carbides. Through a great deal of observation of these particles, it was found that most of the primary carbides are the Mo-Cr-rich carbide, which is in agreement with the previous study ${ }^{[5]}$.

Table 2 lists the average compositions in the interdendritic region just around the primary carbides and dendrite core of the conventionally cast ingot and the segregation ratios (SRs) of the alloying elements (note that experimental quantitative $\mathrm{C}$ analysis
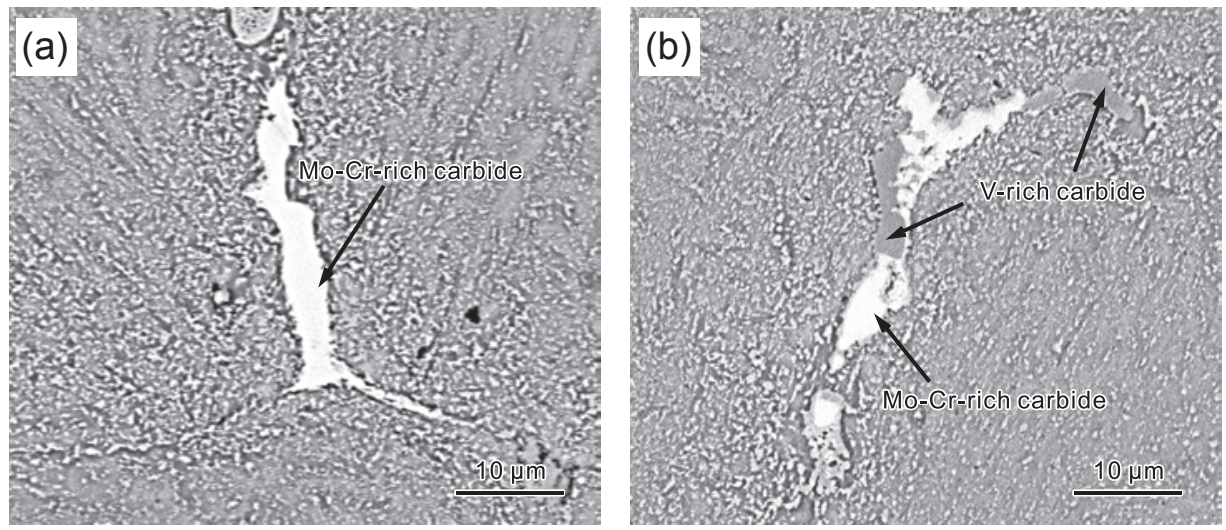

Fig. 3: Morphology of primary carbides precipitated in the interdendritic region of conventionally cast $\mathrm{H} 13$ steel ingot
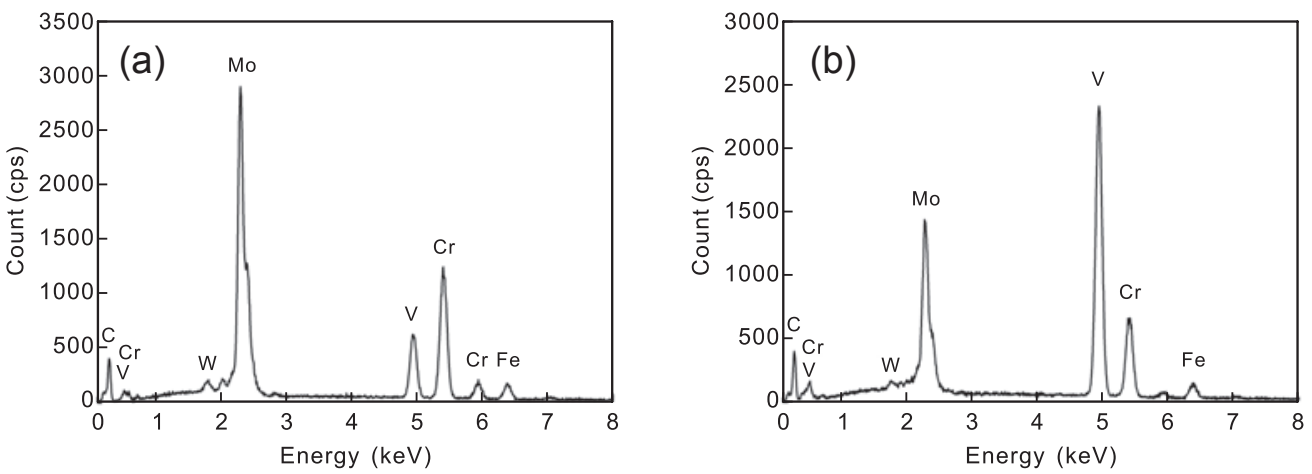

Fig. 4: EDS spectra of Mo-Cr-rich carbide (a) and V-rich carbide (b) 
Table 2: Distribution and SRs of alloying elements in conventionally cast $\mathrm{H} 13$ steel ingot

\begin{tabular}{cccc} 
Elements & $\begin{array}{c}\text { Interdendritic } \\
\text { region }\end{array}$ & Dendrite core & SR \\
\hline Mo & 3.08 & 2.42 & 1.27 \\
$\mathrm{Cr}$ & 8.10 & 6.65 & 1.22 \\
$\mathrm{~V}$ & 1.22 & 0.9 & 1.36 \\
$\mathrm{Si}$ & 1.12 & 1.07 & 1.05 \\
\hline
\end{tabular}

was not feasible due to surface contamination ${ }^{[29]}$ ). It can be seen that the SRs of Mo, Cr and V are markedly greater than 1, but the SR of $\mathrm{Si}$ is just a little greater than 1 . This indicates that the $\mathrm{Mo}, \mathrm{Cr}$ and $\mathrm{V}$ are obviously segregated in the interdendritic region, while the segregation of $\mathrm{Si}$ is negligible.

\subsection{In situ observation of melting process}

Figure 5 shows the recorded microstructures during the heating process. Since the samples were polished to a mirror finish before in situ observations, the primary carbides could be clearly revealed as shown in Fig. 5a. However, the Mo-Cr-rich carbide and V-rich carbide are indistinguishable under the optical microscope attached to the HT-CLSM. A solid-solid transformation occurs at about $850{ }^{\circ} \mathrm{C}$ and finishs at about $951^{\circ} \mathrm{C}$, as shown in Fig. $5 \mathrm{~b}$. According to the transition temperature, this phase transformation should be the austenization. As the temperature increases, the incipient melting firstly occurs along the primary carbides at around $1,190{ }^{\circ} \mathrm{C}$ (Fig. 5c), and the melting process of all the carbide particles occurs within a narrow temperature range (about $20{ }^{\circ} \mathrm{C}$ ). With further increase of temperature, the liquid phase extends gradually from the interdendritic region, where the primary carbides are located, to the dendrite area (Fig. 5e). It is worth noting that there must exist a noticeable temperature gradient within the HT-CLSM samples with the thickness of $3 \mathrm{~mm}$ during the heating process. Owing to the nature of temperature control and the heating principle of the HT-CLSM (Fig. 1a), the actual sample surface temperature should be higher than the temperature measured using the thermocouple ${ }^{[26]}$
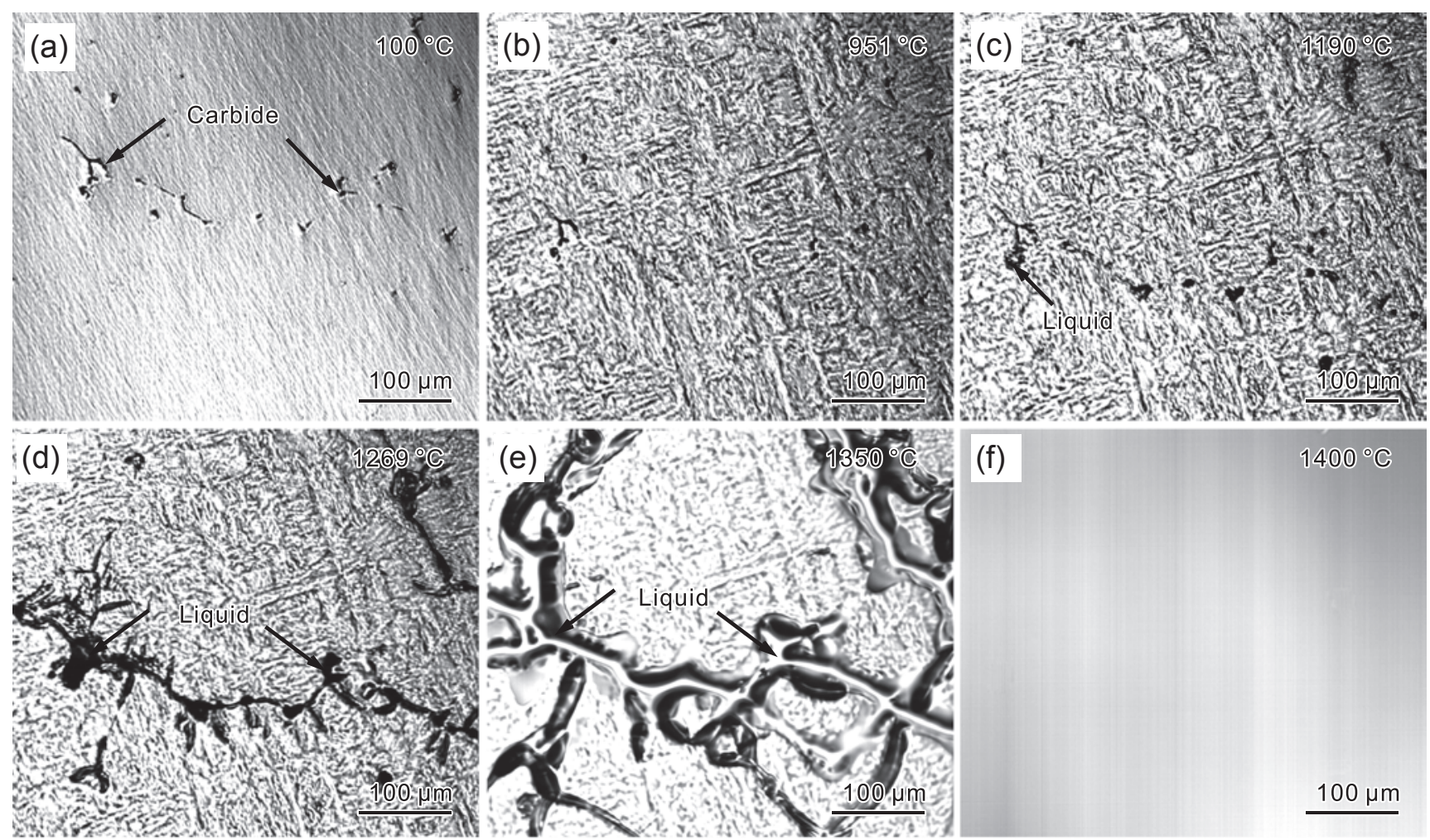

(f)

$1400^{\circ} \mathrm{C}$

Fig. 5: HT-CLSM snapshots for conventionally cast $\mathrm{H} 13$ steel ingot heating from 100 to $1,400{ }^{\circ} \mathrm{C}$ at a heating rate of $180^{\circ} \mathrm{C} \cdot \mathrm{min}^{-1}$

It has been reported that the liquidus temperature, $T_{\mathrm{L}}$, and solidus temperature, $T_{\mathrm{S}}$, of $\mathrm{H} 13$ steel can be calculated as ${ }^{[5,30]}$.

$$
\begin{aligned}
T_{\mathrm{L}}= & T_{0}-88(\text { pct C)}-25(\text { pct S })-8(\text { pct Si })-5(\text { pct Mn })-2(\text { pct Mo }) \\
& -1.5(\text { pct Cr })-2(\text { pct V) }-30(\text { pct } P) \\
T_{\mathrm{S}}= & T_{0}-200(\text { pct C })-12.3(\text { pct Si })-6.8(\text { pct Mn })-124.5(\text { pct P }) \\
& -183.9(\text { pct S })-1.4(\text { pct Cr })
\end{aligned}
$$

where $T_{0}$ is the melting point of pure iron, which is $1,538^{\circ} \mathrm{C}$. Simple calculations show that $T_{\mathrm{L}}$ is $1,463.93{ }^{\circ} \mathrm{C}$ and $T_{\mathrm{S}}$ is $1,403.08^{\circ} \mathrm{C}$.

Apparently, the theoretical liquidus temperature of the experimental $\mathrm{H} 13$ steel is about $64^{\circ} \mathrm{C}$ higher than that determined by the HT-CLSM in-situ observation (about $1,400{ }^{\circ} \mathrm{C}$ ). This also indicates that the actual temperature of the sample surface is obviously higher than the measured temperature. 

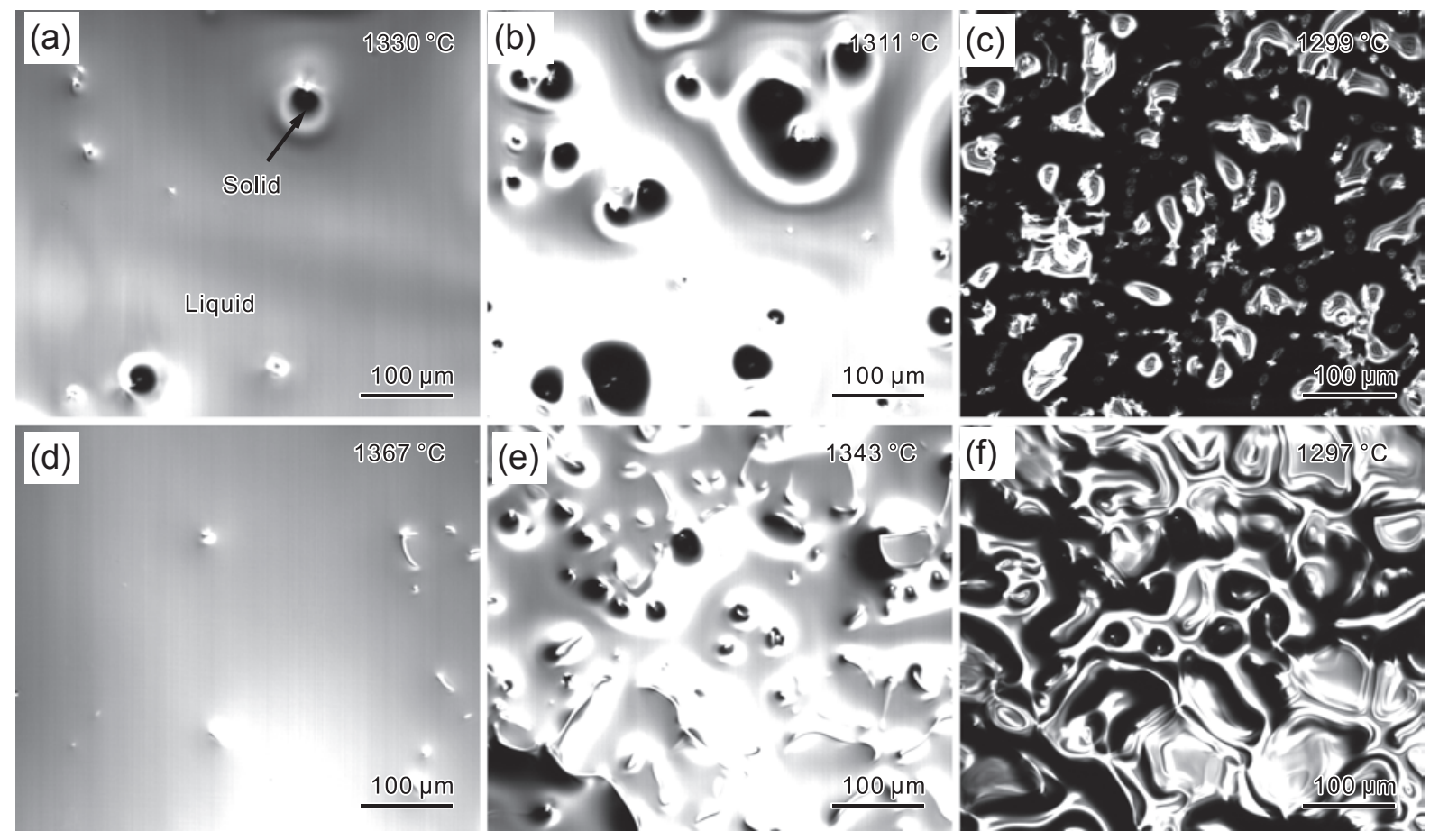

Fig. 6: HT-CLSM snapshots for the sequence of solidification of $\mathrm{H} 13$ steel during cooling at $300^{\circ} \mathrm{C} \cdot \mathrm{min}^{-1}(\mathrm{a}, \mathrm{b}, \mathrm{c})$ and $1,200{ }^{\circ} \mathrm{C} \cdot \mathrm{min}^{-1}(\mathrm{~d}, \mathrm{e}, \mathrm{f})$, respectively

\subsection{In situ observation of solidification process}

Figure 6 shows the recorded microstructures during solidification at a cooling rate of 300 and $1,200{ }^{\circ} \mathrm{C} \cdot \mathrm{min}^{-1}$, respectively. When the cooling rate was $300{ }^{\circ} \mathrm{C} \cdot \mathrm{min}^{-1}$, only a few solid phase particles formed at the initial stage of solidification (Fig. 6b). However, when the cooling rate was increased to $1,200{ }^{\circ} \mathrm{C} \cdot \mathrm{min}^{-1}$, a large number of solid phase particles formed (Fig. 6e). Obviously, the increasing cooling rate significantly increases the nucleation rate of the liquid. Note that the cooling rate of $6,000{ }^{\circ} \mathrm{C} \cdot \mathrm{min}^{-1}$ is too fast for the HT-CLSM to record the solidification process.

Besides, the HT-CLSM in-situ observation also indicates that when the cooling rate was $300{ }^{\circ} \mathrm{C} \cdot \mathrm{min}^{-1}$, the nucleation temperature was about $1,346{ }^{\circ} \mathrm{C}$, and when the cooling rate was $1,200{ }^{\circ} \mathrm{C} \cdot \mathrm{min}^{-1}$, the nucleation temperature was about $1,367{ }^{\circ} \mathrm{C}$. In other words, the increasing cooling rate raises the nucleation temperature. However, this phenomena is contrary to the classic nucleation theory ${ }^{[31]}$. According to the working principle of the present HT-CLSM, the $300{ }^{\circ} \mathrm{C} \cdot \mathrm{min}^{-1}$ cooling process was realized through reducing the input power of the halogen lamp, and in this case, the sample surface temperature should be higher than that of the thermocouple (similar to the heating process). However, the $1,200{ }^{\circ} \mathrm{C} \cdot \mathrm{min}^{-1}$ cooling process was achieved mainly by filling the chamber with $\mathrm{He}$ gas. The flow pattern of $\mathrm{He}$ in the chamber causes that it must reach the sample surface earlier than the thermocouple. Moreover, the contact area between the sample surface and He is much larger than that between the thermocouple and He. Thus the sample surface was more rapidly cooled and its temperature should be lower than that of the thermocouple during the $1,200{ }^{\circ} \mathrm{C} \cdot \mathrm{min}^{-1}$ cooling process. In other words, although the actual temperature of the sample surface has decreased greatly after being cooled at $1,200{ }^{\circ} \mathrm{C} \cdot \mathrm{min}^{-1}$ for a certain time, the thermocouple still stay at a higher temperature. This causes a false appearance that the increasing cooling rate raises the nucleation temperature.

\subsection{Effect of cooling rate on solidification microstructure}

Figure 7 shows the optical micrographs of the HT-CLSM samples solidified at different cooling rates. Apparently, the dendritic structure is significantly refined and the interdendritic areas are obviously narrowed by the increasing cooling rate. Through the above in situ observation of solidification processes (Fig. 6), it is easy to understand that the microstructure refinement is due to the increasing nucleation rate with the increase of cooling rate.

The SDAS is an important characteristic of solidification microstructures, which indicates the diffusion path length and can have significant influences on the micro-segregation. It has been reported that the SDAS, $\lambda_{2}$, can be expressed as a function of cooling rate, $\dot{T}^{[31,32]}$.

$$
\lambda_{2}=\varepsilon \dot{T}^{-n}
$$

where $\varepsilon$ is a constant and $n$ is the exponent. The $\varepsilon$ and $n$ can be obviously influenced by the change of cooling rate and composition ${ }^{[33]}$. The measured SDASs of the HT-CLSM samples solidified at different cooling rates are shown in Fig. 7(d), and the fitted curve of SDASs as a function of cooling rate in the form of Eq. (4) can be expressed as:

$$
\lambda_{2}=128.45 \dot{T}^{-0.124}
$$

It can be seen that the SDAS decreases gradually with the increase of cooling rate. Besides, the SDASs of all these HT-CLSM 

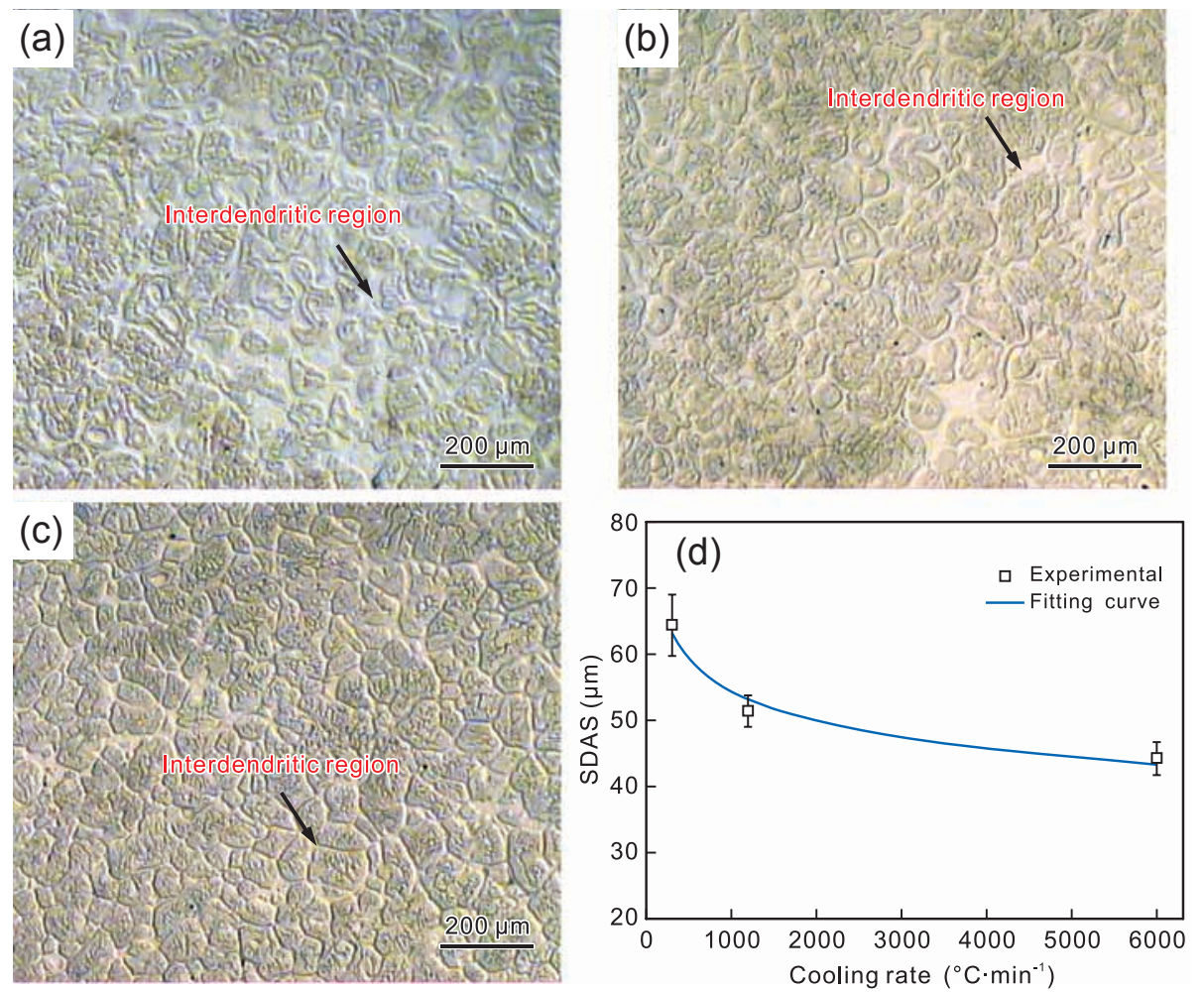

Fig. 7: Dendritic structures of HT-CLSM samples solidified at cooling rates of $300^{\circ} \mathrm{C} \cdot \mathrm{min}^{-1}(\mathrm{a}), 1,200^{\circ} \mathrm{C} \cdot \mathrm{min}^{-1}(\mathrm{~b})$, and $6,000{ }^{\circ} \mathrm{C} \cdot \mathrm{min}^{-1}(\mathrm{c})$, and SDAS as a function of cooling rate (d)

samples are much finer than that of the conventionally cast ingot.

Microstructures of the HT-CLSM samples solidified at different cooling rates were further observed under the SEMBSE, and compositions of the primary carbides were analyzed using EDS. As consistent with that of the conventionally cast ingot, two kinds of primary carbides, i.e., the Mo-Cr-rich carbide and V-rich carbide, formed along the interdendritic region and most of them are the Mo-Cr-rich carbide as shown in Fig. 8. Besides, the Mo-Cr-rich carbide is always attached to the V-rich carbide. When the cooling rate is $300{ }^{\circ} \mathrm{C} \cdot \mathrm{min}^{-1}$, the Mo-Cr-rich carbides are mainly in eutectic-like and long strip-like shapes, while the V-rich carbides are normally in rodlike and block shapes (Figs. 8a, b and c). When the cooling rate increases to $1,200{ }^{\circ} \mathrm{C} \cdot \mathrm{min}^{-1}$, the primary carbides become finer, but their morphologies are not obviously changed (Figs. $8 \mathrm{~d}, 8 \mathrm{e}$ and $8 \mathrm{f}$ ). When the cooling rate is further increased to $6,000{ }^{\circ} \mathrm{C} \cdot \mathrm{min}^{-1}$, the primary carbides are further refined and the V-rich carbide also becomes eutectic-like and long strip-like (Figs. 8g, 8h and 8i). Besides, compared with the carbides in the conventionally cast ingot as shown in Fig. 3, the primary carbides in the HT-CLSM samples are much finer and their morphologies are quite different. It has been reported that the cooling rate of the conventional casting process locates within $0.1-20{ }^{\circ} \mathrm{C} \cdot \mathrm{min}^{-1}{ }^{[27,34]}$. Thus, it can be concluded that the increasing cooling rate refines the primary carbides and promotes the change of the carbide morphology from blocky to eutectic-like and long strip-like, especially when the cooling rate is increased above $300{ }^{\circ} \mathrm{C} \cdot \mathrm{min}^{-1}$.

Figure 9 shows the variations of volume fractions of the MoCr-rich carbide and V-rich carbide in the HT-CLSM samples as a function of cooling rates. Despite different cooling rates, the fraction of the Mo-Cr-rich carbide is much greater than that of the V-rich carbide. The volume fractions of both primary carbides decrease gradually with the increase of cooling rate. The volume fraction of the primary carbides (including the MoCr-rich carbide and V-rich carbide) in the HT-CLSM sample solidified at $300{ }^{\circ} \mathrm{C} \cdot \mathrm{min}^{-1}$ is about $0.29 \%$, which is much smaller than that in the conventionally cast ingot $(0.53 \%)$. In general, the precipitation of the primary carbides is markedly reduced by the increasing cooling rate, but it cannot be inhibited even when the cooling rate is increased to $6,000{ }^{\circ} \mathrm{C} \cdot \mathrm{min}^{-1}$.

\subsection{Effect of cooling rate on micro-segregation}

To clarify whether the influence of cooling rate on primary carbides precipitation is related to the elemental segregation, average compositions in the interdendritic region and dendrite core of the HT-CLSM samples solidified at different cooling rates were determined, and SRs of the carbide forming elements $\mathrm{Mo}, \mathrm{Cr}$ and $\mathrm{V}$ were calculated. The results are shown in Fig. 10. It can be seen that regardless of the cooling rate, the average concentrations of $\mathrm{Mo}, \mathrm{Cr}$ and $\mathrm{V}$ in the interdendritic region are obviously greater than those in the dendrite core. In the cooling rate range investigated, the cooling rate has little influence on the average concentrations of these elements in both the interdendritic region (Fig. 10a) and dendrite core (Fig. 10b), and as a result, their SRs are hardly affected by the cooling rate (Fig. 10c).

However, compared to the conventionally cast ingot (Table 2), the SRs of Mo, Cr and V in the HT-CLSM samples are obviously greater. Besides, Mao et al. ${ }^{[5]}$ found that at lower cooling rates $\left(5-20{ }^{\circ} \mathrm{C} \cdot \mathrm{min}^{-1}\right)$, the SRs of these elements in $\mathrm{H} 13$ steel 

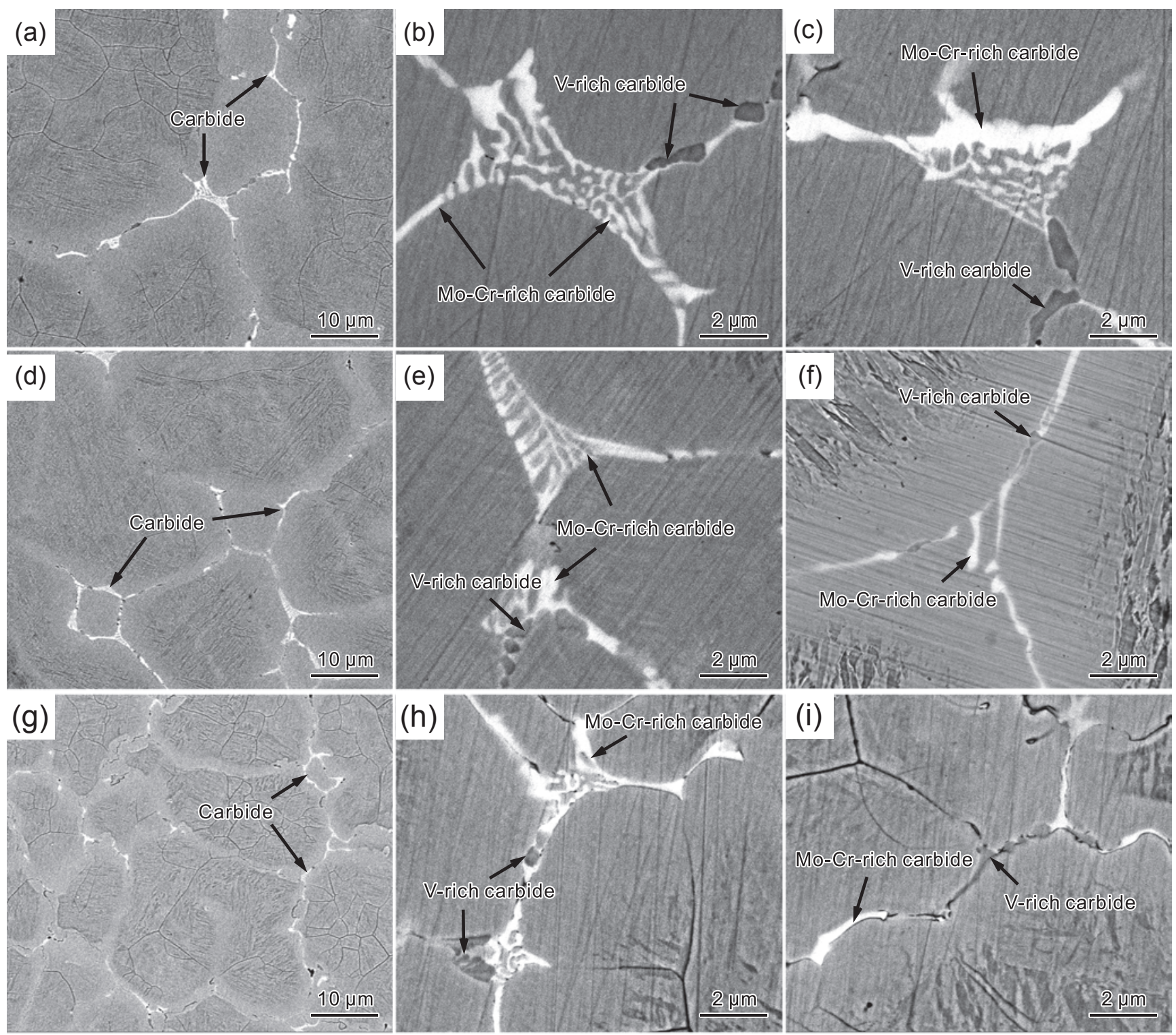

Fig. 8: Morphologies of primary carbides precipitated in HT-CLSM samples solidified at $300^{\circ} \mathrm{C} \cdot \mathrm{min}^{-1}(\mathrm{a}, \mathrm{b}, \mathrm{c})$, $1,200^{\circ} \mathrm{C} \cdot \mathrm{min}^{-1}(\mathrm{~d}, \mathrm{e}, \mathrm{f})$ and $6,000^{\circ} \mathrm{C} \cdot \mathrm{min}^{-1}(\mathrm{~g}, \mathrm{~h}, \mathrm{i})$

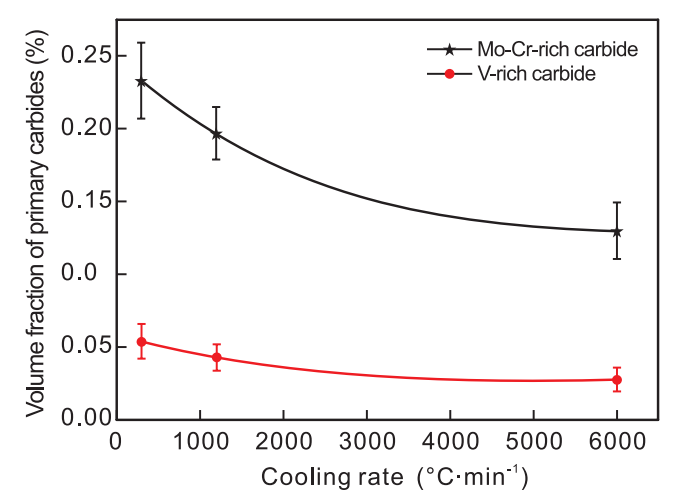

Fig. 9: Volume fractions of the primary carbides precipitated in HT-CLSM samples solidified at different cooling rates

were significantly increased by the increasing cooling rate. Thus, it can be concluded that the degree of the Mo, $\mathrm{V}$ and $\mathrm{Cr}$ segregation is increased by the increase of cooling rate in the low cooling rate range, but when the cooling rate is further increased above a critical value (at most $300{ }^{\circ} \mathrm{C} \cdot \mathrm{min}^{-1}$ ), it remains almost constant.

During the solidification of alloys, the back diffusion of alloying elements is an important factor that determines the solidification segregation ${ }^{[5,35]}$. According to the Clyne-Kurz model which considers the solid state back diffusion ${ }^{[36]}$, the solute concentration in the liquid is given by:

$$
\begin{gathered}
C_{\mathrm{L}}=C_{0}\left[1-(1-2 \Omega(\alpha) k) f_{\mathrm{s}}\right]^{\frac{k-1}{1-2 \Omega(\alpha) k}} \\
\Omega(\alpha)=\alpha\left[1-\exp \left(-\frac{1}{\alpha}\right)\right]-\frac{1}{2} \exp \left(-\frac{1}{2 \alpha}\right) \\
\alpha=\frac{D_{\mathrm{s}} t_{\mathrm{f}}}{L^{2}}=\frac{4 D_{\mathrm{s}} \Delta T_{\mathrm{f}}}{\lambda_{2}^{2} \dot{T}} \\
\Delta T_{\mathrm{f}}=T_{\mathrm{L}}-T_{\mathrm{S}}
\end{gathered}
$$



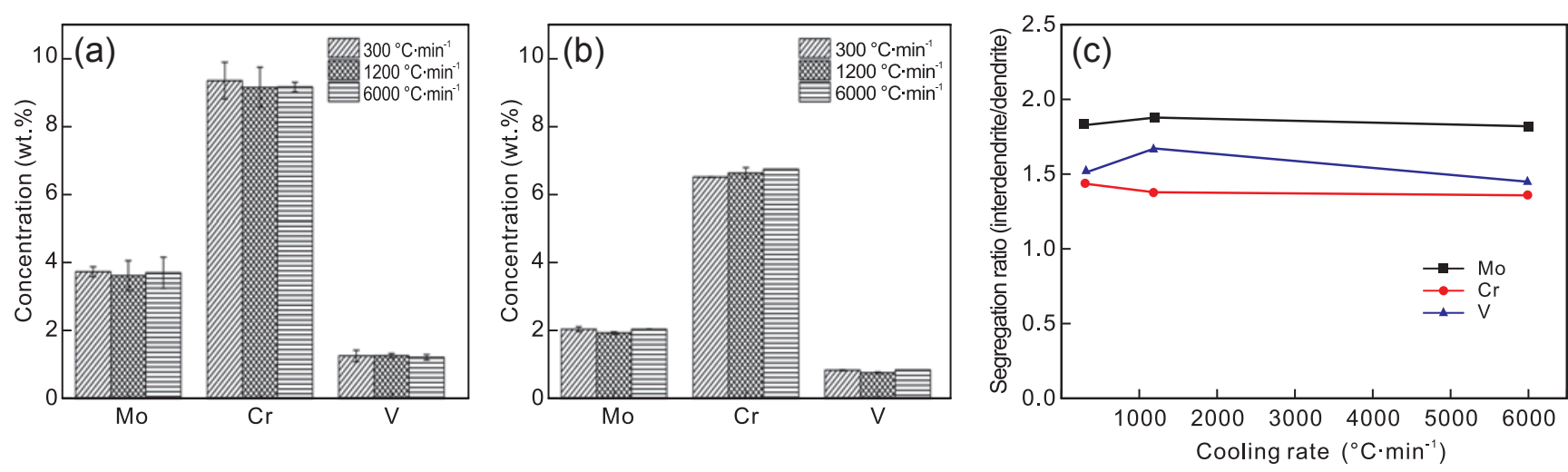

Fig. 10: Average concentrations of carbide forming elements $\mathrm{Mo}, \mathrm{Cr}$ and $\mathrm{V}$ in the interdendritic region (a) and dendrite core (b) of HT-CLSM samples solidified at different cooling rates, and their segregation ratios (c)

where $C_{\mathrm{L}}$ is the solute concentration in liquid, $C_{0}$ is the initial solute concentration, $\Omega(\alpha)$ is the dimensionless parameter representing the extent of back-diffusion in solid, $f_{\mathrm{s}}$ is the solid fraction, $k$ is the partition coefficient of alloying elements, $D_{\mathrm{s}}$ is the diffusion coefficient of alloying elements in solid, $t_{\mathrm{f}}$ is the local solidification time, $L$ is the diffusion path length, $\dot{T}$ is the local cooling rate, $\Delta T_{\mathrm{f}}$ is the solidification range, and $\lambda_{2}$ is the SDAS.

As the $\Omega(\alpha)$ values approach zero, the Clyne-Kurz model will reduce to the Scheil model which ignores the solid state back diffusion of alloying elements ${ }^{[35]}$. The calculated $\Omega(\alpha)$ values for the carbide forming elements $\mathrm{Mo}, \mathrm{Cr}, \mathrm{V}$ and $\mathrm{C}$ at various cooling rates are listed in Table 3 . The $D_{\mathrm{s}}$ in Eq. (8) was calculated at the mid temperature $\left(T_{\text {mid }}\right)$ between $T_{\mathrm{L}}$ and $T_{\mathrm{S}}$. Relations of $D_{\mathrm{s}}$ values $\left(\mathrm{cm}^{2} \cdot \mathrm{s}^{-1}\right)$ for $\mathrm{Mo}, \mathrm{Cr}, \mathrm{V}$ and $\mathrm{C}$ with

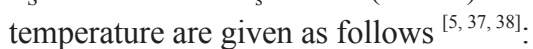

$$
\begin{aligned}
& D_{\mathrm{s}, \mathrm{Mo}}=0.068 \exp (-246868 / R T) \\
& D_{\mathrm{s}, \mathrm{Cr}}=0.0012 \exp (-219001 / R T) \\
& D_{\mathrm{s}, \mathrm{V}}=0.248 \exp (-259002 / R T) \\
& D_{\mathrm{s}, \mathrm{C}}=0.0761 \exp (-143511 / R T)
\end{aligned}
$$

where $R$ is the gas constant of $8.314 \mathrm{~J} \cdot \mathrm{mol}^{-1} \cdot \mathrm{K}^{-1}$ and $T$ is the temperature in Kelvin.

It can be seen from Table 3 that the calculated $\Omega(\alpha)$ values of all these elements definitely decrease with the increase of cooling rate, which suggests that the dilution influence of back diffusion on micro-segregation is reduced by the increase of cooling rate. Besides, the $\Omega(\alpha)$ values of Mo, $\mathrm{Cr}$ and $\mathrm{V}$ are very small and very close to zero, indicating that the back diffusion

Table 3: Calculated $\Omega(\alpha)$ values of the carbide forming elements at various cooling rates

\begin{tabular}{ccccc}
$\begin{array}{c}T \\
\left({ }^{\circ} \mathbf{C} \cdot \mathbf{m i n}^{-1}\right)\end{array}$ & Mo & $\mathbf{C r}$ & $\mathbf{V}$ & $\mathbf{C}$ \\
\hline 300 & $2.22 \times 10^{-3}$ & $2.81 \times 10^{-4}$ & $3.46 \times 10^{-3}$ & 3.62 \\
1,200 & $8.73 \times 10^{-4}$ & $1.10 \times 10^{-4}$ & $1.36 \times 10^{-3}$ & 1.42 \\
6,000 & $2.36 \times 10^{-4}$ & $2.98 \times 10^{-5}$ & $3.66 \times 10^{-4}$ & 0.38
\end{tabular}

of these elements are nearly suppressed when the cooling rate is increased above $300{ }^{\circ} \mathrm{C} \cdot \mathrm{min}^{-1}$. Seo et al. ${ }^{[35]}$ also proved similar results, i.e., the back diffusion in solid phase of Ni-based superalloys is gradually deactivated as the cooling rate increases and becomes too small to influence the micro-segregation when the cooling rate is increased above a critical value. It is worth noting that since the cooling rates for conventional casting processes are much lower, the back diffusion of the carbide forming elements in the conventionally cast ingot must be more significant than that in the HT-CLSM samples solidified at relatively higher cooling rates $\left(300-6,000{ }^{\circ} \mathrm{C} \cdot \mathrm{min}^{-1}\right)$. Most likely, the influence of cooling rate on the back diffusion extent can be considered to be the reason why the SRs of $\mathrm{Mo}, \mathrm{Cr}$ and $\mathrm{V}$ are not obviously influenced by the cooling rate in the investigated cooling rate range, but the SRs of these elements in the HT-CLSM samples are obviously greater than those in the conventionally cast ingot.

It has been found that the segregation of $\mathrm{C}$ in $\mathrm{H} 13$ steel almost follows the Lever-rule model which assumes that the alloying elements are uniformly distributed in the solid during solidification ${ }^{[5,39]}$, and this may be due to the large diffusion coefficient of $\mathrm{C}$ in the solid ${ }^{[5,37,38]}$. Moreover, Lippard et al. ${ }^{[29]}$ found that the segregation of $\mathrm{C}$ in sand casting AerMet 100 steel is not obvious by the DICTRA calculation (the SR of C is only 1.12). Thus, it is believed that $C$ tends to be distributed uniformly between the dendrite core and interdendritic region. In this case, the influence of back diffusion extent on the segregation degree of $\mathrm{C}$ will be very limited. Although the $\Omega(\alpha)$ value of $\mathrm{C}$ decreases significantly with the increase of cooling rate (Table 3 ), the SR of C could only be slightly enlarged by the increasing cooling rate.

\section{Discussion}

Although the SRs of the carbide forming elements are hardly influenced by the cooling rate in the investigated cooling rate range $\left(300-6,000{ }^{\circ} \mathrm{C} \cdot \mathrm{min}^{-1}\right)$, the primary carbides precipitation is obviously reduced by the increasing cooling rate in this range. Moreover, despite the lower SRs of carbide forming elements in the conventionally cast ingot, the volume fraction 
of primary carbides in the ingot is obviously larger than that in the HT-CLSM samples. Therefore, the change in the primary carbides' characteristics is not due to the variation of the degree of alloying elements segregation.

As mentioned above, the increasing cooling rate obviously increases the nucleation rate and hence decreases the SDAS, which in turn narrows the remaining liquid pools between the dendrites where the primary carbides are formed. Thus, at relatively higher cooling rates $\left(300-6,000{ }^{\circ} \mathrm{C} \cdot \mathrm{min}^{-1}\right)$, the remaining liquid presents as thin films, and in this case the primary carbides have to grow along the thin films and become long strip-like. According to the principles of solidification, when the cooling rate increases to a certain value, the melt can be undercooled into the pseudo-eutectic region ${ }^{[40]}$. This may be the main cause of the eutectic-like primary carbides precipitation in the HT-CLSM samples. Since the content of the V-rich carbide forming element $\mathrm{V}$ in this steel is much lower than those of the Mo-Cr-rich carbide forming elements Mo and Cr, compared with the long strip-like Mo-Cr-rich carbide, the formation of long strip-like V-rich carbide needs thinner liquid films. Besides, the lower $\mathrm{V}$ content also makes it more difficult for the V-rich carbide forming elements to reach the eutectic points. Thus, the cooling rate needed for the long strip-like and eutectic-like V-rich carbides precipitation is higher than that for the long strip-like and eutectic-like Mo-Cr-rich carbides precipitation (Fig. 8).

Since the remaining liquid films between the dendrites are narrowed by the increase of cooling rate, finer primary carbides must be formed along the thinner liquid films. The refinement of the carbides naturally leads to the decrease of their volume fractions. As mentioned above, the content of $\mathrm{V}$ is much lower than that of Mo and Cr, so the volume fraction of the V-rich carbide is obviously smaller than that of the Mo-Cr-rich carbide regardless of the cooling rate.

Additive Manufacturing (AM) is a promising manufacturing technology for H13 and other hot-work tool steels. This paper reveals that at relatively high cooling rates (300$6,000{ }^{\circ} \mathrm{C} \cdot \mathrm{min}^{-1}$ ), the primary carbides precipitated along the interdendritic region of $\mathrm{H} 13$ steel are mainly the eutectic-like and long strip-like Mo-Cr-rich carbide, and the increasing cooling rate obviously refines the primary carbides and reduces their volume fractions. When the AM process is performed, the variation of the primary carbides characteristics with the cooling rate needs to be considered to better control the final properties of these steels.

\section{Conclusions}

This study mainly investigated the primary carbides precipitation in $\mathrm{H} 13$ steel solidified at relatively high cooling rates, ranging from 300 to $6,000{ }^{\circ} \mathrm{C} \cdot \mathrm{min}^{-1}$, based on in situ observations with HT-CLSM. The conclusions as follows are gathered:

(1) In the cooling rate range investigated, the solidified microstructure is obviously refined by the increased cooling rate, and the SDAS, $\lambda_{2}$, as a function of cooling rate, $\dot{T}$, is experimentally evidenced as $\lambda_{2}=128.45 \dot{T}^{-0.124}$.
(2) In the cooling rate range investigated, two kinds of primary carbides, namely Mo-Cr-rich carbide and V-rich carbide, are precipitated at the final solidification stage, and the amount of Mo-Cr-rich carbide is much larger than that of V-rich carbide. The cooling rate has no obvious influence on the Mo-Cr-rich carbide morphology, but has a significant effect on the V-rich carbide morphology. The increase of cooling rate markedly refines the primary carbides and obviously reduces their volume fractions. Besides, the segregation ratios of the carbides forming elements $\mathrm{Mo}, \mathrm{Cr}$ and $\mathrm{V}$ are insensitive to the cooling rate.

(3) Compared with the conventionally cast ingot, the SDASs of the steel solidified at the investigated cooling rates are much smaller, the primary carbides formed in the steel solidified at the investigated cooling rates are much finer and their morphologies have changed significantly. Moreover, segregation ratios of the carbides forming elements in the steel solidified at the investigated cooling rates are obviously greater.

\section{Acknowledgments}

This work was financially supported by the National Natural Science Foundation of China (Grant No. 51904146), the Doctor Start-up Fund of Liaoning Province (Grant No. 2019-BS-125), and the National Key Laboratory of Marine Engineering of China (Grant No. SKLMEA-USTL-201707).

\section{References}

[1] Gualco A, Svoboda H G, Surian E S, et al. Effect of welding procedure on wear behaviour of a modified martensitic tool steel hard facing deposit. Mater. Des., 2010, 31: 4165-4173.

[2] Handbook ASM. Vol. 1 - Properties and selection: irons, steels, and high-performance alloys. ASM International, Materials Park, OH. 1990, 44073: 140-194.

[3] Rafi H K, Ram G J, Phanikumar G, et al. Microstructural evolution during friction surfacing of tool steel H13. Mater. Des., 2011, 32: 82-87.

[4] Cong D, Zhou H, Yang M, et al. The mechanical properties of $\mathrm{H} 13$ die steel repaired by a biomimetic laser technique. Optics \& Laser Technology, 2013, 53: 1-8.

[5] Mao M, Guo H, Wang F, et al. Effect of cooling rate on the solidification microstructure and characteristics of primary carbides in H13 steel. ISIJ Int., 2019, 59(5): 848-857.

[6] McHugh K, Lin Y, Zhou Y, et al. Influence of cooling rate on phase formation in spray-formed $\mathrm{H} 13$ tool steel. Mater. Sci. Eng. A, 2008, 477: 50-57.

[7] Kheirandish S, Noorian A. Effect of niobium on microstructure of cast AISI H13 hot work tool steel. J. Iron. Steel Res. Int., 2008, 15: 61-66.

[8] Ozaki K. Effect of the distribution of primary carbide on fatigue strength of cold work die steels. Electric Furnace Steel, 2005, 76: 249-257. (In Japanese)

[9] Mishnaevsky L L, Lippmann Jr N, Schmauder S. Micromechanisms and modelling of crack initiation and growth in tool steels: role of primary carbides. Materials Research and Advanced Techniques, 2003, 94: 676-681.

[10] Mesquita R A. Tool steels: properties and performance, CRC Press Taylor \& Francis Group, Boca Raton, Florida, USA, 2016.

[11] Pryds N, Huang $X$. The effect of cooling rate on the microstructures formed during solidification of ferritic steel. Metall. Mater. Trans. A, 2000, 31: 3155-3166. 
[12] Fernandez R, Lecomte J, Kattamis T. Effect of solidification parameters on the growth geometry of $\mathrm{MC}$ carbide in $\mathrm{IN}-100$ dendritic monocrystals, Metall. Trans. A, 1978, 9: 1381-1386.

[13] Reed R C. The superalloys: fundamentals and applications. Cambridge University Press, New York, USA, 2008.

[14] Hopkinson N, Hague R, Dickens P. Rapid manufacturing - An industrial revolution for the digital age. John Wiley \& Sons. Inc., Chichester, England, 2006.

[15] Hofmann D C, Roberts S, Otis R, et al. Developing gradient metal alloys through radial deposition additive manufacturing. Scientific Reports, UK., 2014, 4: 5357.

[16] Helmer H E, Körner C, Singer R F. Additive manufacturing of nickel-based superalloy Inconel 718 by selective electron beam melting: Processing window and microstructure. J. Mater. Res., 2014, 29: 1987-1996.

[17] Xiao H, Li S, Xiao W, et al. Effects of laser modes on $\mathrm{Nb}$ segregation and Laves phase formation during laser additive manufacturing of nickel-based superalloy. Mater. Lett., 2017 , 188: 260-262.

[18] Basak A, Acharya R, Das S. Additive manufacturing of singlecrystal superalloy CMSX-4 through scanning laser epitaxy: computational modeling, experimental process development, and process parameter optimization. Metall. Mater. Trans. A, 2016, 47: 3845-3859.

[19] Islam M, Purtonen T, Piili $\mathrm{H}$, et al. Temperature profile and imaging analysis of laser additive manufacturing of stainless steel. Physics Procedia., 2013, 41: 835-842.

[20] Francois M M, Sun A, King W E, et al. Modeling of additive manufacturing processes for metals: Challenges and opportunities. Curr. Opin. Solid State Mater. Sci., 2017, 21: 198-206.

[21] Ho A, Zhao H, Fellowes J W, et al. On the origin of microstructural banding in Ti-6AI4V wire-arc based high deposition rate additive manufacturing. Acta Mater., 2019, 166: 306-323.

[22] Klocke F, Arntz K, Teli M, et al. State-of-the-art laser additive manufacturing for hot-work tool steels. Procedia CIRP., 2017, 63: 58-63.

[23] Gu G, Pesci R, Langlois L, et al. Microstructure observation and quantification of the liquid fraction of M2 steel grade in the semi-solid state, combining confocal laser scanning microscopy and X-ray microtomography. Acta Mater., 2014, 66: $118-131$

[24] Kim J H, Kim S G, Inoue A. In situ observation of solidification behavior in undercooled Pd-Cu-Ni-P alloy by using a confocal scanning laser microscope. Acta Mater., 2001, 49: 615-622.
[25] Sohn I, Dippenaar R. In-Situ observation of crystallization and growth in high-temperature melts using the confocal laser microscope. Metall. Mater. Trans. B, 2016, 47: 2083-2094.

[26] Attallah M M, Terasaki H, Moat R J, et al. In-situ observation of primary $\mathrm{Y}^{\prime}$ melting in Ni-base superalloy using confocal laser scanning microscopy. Mater. Charact., 2011, 62: 760-767.

[27] Ling L, Han Y, Zhou W, et al. Study of microsegregation and Laves phase in Inconel718 superalloy regarding cooling rate during solidification. Metall. Mater. Trans. A, 2015, 46: 354-361.

[28] Hobbs R, Tin S, Rae C. A castability model based on elemental solid-liquid partitioning in advanced nickel-base single-crystal superalloys. Metall. Mater. Trans. A, 2005, 36: 2761-2773.

[29] Lippard H E, Campbell C E, Dravid V P, et al. Microsegregation behavior during solidification and homogenization of AerMet100 steel. Metall. Mater. Trans. B, 1998, 29: 205-210.

[30] Thomas B G, Samarasekera I V and Brimacombe J K. Mathematical model of the thermal processing of steel ingots: Part I. Heat flow model. Metall. Mater. Trans. B, 1987, 18: 119-130.

[31] Kurz W, Fisher D J. Fundamentals of solidification. Trans Tech Publications Ltd, Switzerland, 1989.

[32] Quaresma J M, Santos C A, Garcia A. Correlation between unsteady-state solidification conditions, dendrite spacings, and mechanical properties of Al-Cu alloys. Metall. Mater. Trans. A, 2000, 31: 3167-3178.

[33] Bouchard D, Kirkaldy J S. Prediction of dendrite arm spacings in unsteady- and steady-state heat flow of unidirectionally solidified binary alloys. Metall. Mater. Trans. B, 1997, 28: 651-663.

[34] Zhang Y, Huang Y, Yang L, et al. Evolution of microstructures at a wide range of solidification cooling rate in a Ni-based superalloy. J. Alloys Compd., 2013, 570: 70-75.

[35] Seo S, Lee J, Yoo Y, et al. A comparative study of the $\mathrm{Y} / \mathrm{Y}^{\prime}$ eutectic evolution during the solidification of $\mathrm{Ni}$-base superalloys. Metall. Mater. Trans. A, 2011, 42: 3150-3159.

[36] Clyne T, Kurz W. Solute redistribution during solidification with rapid solid state diffusion. Metall. Trans. A, 1981, 12: 965-971.

[37] Meng Y, Thomas B G. Heat-transfer and solidification model of continuous slab casting: CON1D. Metall. Mater. Trans. B, 2003, 34: 685-705.

[38] Ueshima Y, Mizoguchi S, Matsumiya T, et al. Analysis of solute distribution in dendrites of carbon steel with $\delta / Y$ transformation during solidification. Metall. Mater. Trans. B, 1986, 17: 845-859.

[39] Flemings M C. Solidification processing, McGraw-Hill, New York, 1974: 2121-2134.

[40] Glicksman M E. Principles of solidification: an introduction to modern casting and crystal growth concepts. Springer Science \& Business Media, 2010. 